\title{
Review of: "Subsoil-potassium depletion accounts for the nutrient budget in high-potassium agricultural soils"
}

\author{
Wei Zhao ${ }^{1}$ \\ 1 Northwest A\&F University
}

Potential competing interests: The author(s) declared that no potential competing interests exist.

This paper assessed continuous potassium (K) removal without replenishment in Argentinean soils. Topsoil exchangeable-K levels under agriculture resulted $48 \%$ lower than their pristine conditions, although still above response levels. Both soil exchangeable-K and slowly- exchangeable K vertical distribution patterns $(0-100 \mathrm{~cm})$ displayed substantial depletion relative to pristine conditions, mainly concentrated at subsoil (20-100 cm). Higher pristine levels of exchangeable-K and slowly-exchangeable-K and lower clay and silt contents resulted in higher soil-K depletion. Soil K management guidelines should consider both topsoil and subsoil nutrient status and variables related to soil $\mathrm{K}$ buffer capacity.

There are several concerns with this study which include the following:

1. $\mathrm{K}$ in plant litter can be leachable in large quantities whether the litter is decomposed or not (see https://www.sciencedirect.com/science/article/pii/S0265931X20300953). The assumption by authors that negligible $\mathrm{K}$ losses from leaching and/or runoff seems not reasonable.

2. According to the Methods section, crop residues were not removed or grazed. Thus, $\mathrm{K}$ in residues will leach into the topsoil after the crop residues decomposed. The $\mathrm{K}$ replenishment resulted from the decomposition of crop residues at the topsoil can underestimate the $\mathrm{K}$ uptake by crops from the topsoil.

3.This paper discussed only $\mathrm{K}$ element budget and no other nutrient element budget. Thus, the term "nutrient budget" in the title of the paper seems inappropriate. 